\title{
Predicting the Ambulatory Status of Patients Irradiated for Metastatic Spinal Cord Compression (MSCC) from Head-and-neck Cancer
}

\author{
DIRK RADES ${ }^{1}$, CHRISTIAN STAACKMANN ${ }^{1}$ and STEFAN JANSSEN ${ }^{1,2}$ \\ ${ }^{1}$ Department of Radiation Oncology, University of Lübeck, Lübeck, Germany; \\ ${ }^{2}$ Private Practice of Radiation Oncology, Hannover, Germany
}

\begin{abstract}
Background/Aim: Personalized cancer care can improve patient outcomes and is facilitated by scoring systems. This study aimed to create an instrument to estimate ambulatory status after radiotherapy for metastatic spinal cord compression (MSCC) from head-and-neck cancer. Patients and Methods: In 60 patients, fractionation regimen plus 10 pretreatment factors were analyzed for post-treatment ambulatory status. Significant factors were used for the scoring system by dividing the ambulatory rate (in \%) by 10. Patients' scores were received by adding the factor scores. Results: Time developing motor deficits $>7$ days $(p=0.011)$, being ambulatory prior to radiotherapy $(p<0.001)$ and ECOG performance score $1-2(p<0.001)$ showed significant associations with posttreatment ambulatory status. Patients' scores were 7, 12, 15, 20, 22 and 27 points. Three groups were designed (7-12, 1520 and 22-27 points) with post-treatment ambulatory rates of $11 \%, 62 \%$ and $96 \%(p<0.001)$. Conclusion: This scoring system helps predict ambulatory status after radiotherapy for MSCC from head-and-neck cancer.
\end{abstract}

Metastatic spinal cord compression (MSCC) is generally associated with neurologic dysfunction mainly with motor deficits $(1,2)$. For these patients, maintaining or regaining the ability to walk, either with or without aid, is a very important endpoint. This may be achieved with radiotherapy alone, which still is the most frequent treatment for MSCC (3-5). In case of inadequate response to radiotherapy patients may not be able to walk after treatment and might have done

Correspondence to: Dirk Rades, MD, Department of Radiation Oncology, University of Lübeck, Lübeck, Ratzeburger Allee 160, 23562 Lübeck, Germany. Tel: +49 45150045401, Fax: +49 45150045404, e-mail: Rades.Dirk@gmx.net

Key Words: Metastatic spinal cord compression, head-and-neck cancer, radiotherapy, post-treatment ambulatory status, scoring system. better with upfront decompressive surgery plus stabilization $(6,7)$. However, upfront surgery has been reported to be associated with severe complications in more than $10 \%$ of the patients and is generally reserved for selected patients with a good performance status and a relatively favorable survival prognosis (6-8). In order to assign the most appropriate treatment protocol to a patient with MSCC, it would be helpful to be able to estimate the patient's ambulatory status following radiotherapy alone. Since MSCC is considered an oncologic emergency and, therefore, treatment decisions have to be made fast, a simple scoring system would be of great value for clinicians that helps predict post-treatment ambulatory status following radiotherapy alone $(1,2)$.

It has been previously stated that it is reasonable to identify predictive factors and develop scoring systems specifically for single tumor entities associated with MSCC due to differences, for example, with respect to tumor biologies, patterns of metastatic spread and survival prognoses (9-15). Therefore, the present study aims to create a scoring system that supports clinicians to estimate the posttreatment ambulatory status of patients irradiated for MSCC, particularly for those patients with MSCC from head-andneck cancer.

\section{Patients and Methods}

Sixty patients who had been treated with radiotherapy alone for motor deficits due to MSCC from head-and-neck cancer between 1997 and 2015 were retrospectively evaluated for ambulatory status at 1 month following irradiation. The fractionation regimen (shortcourse radiotherapy $(1 \times 8$ Gy or $5 \times 4$ Gy) vs. $10 \times 3$ Gy vs. longercourse radiotherapy with total doses $>30$ Gy $(15 \times 2.5$ Gy or $20 \times 2$ Gy)) plus 10 pre-treatment factors were analyzed. The pre-treatment factors included age ( $\leq 59$ years $v s . \geq 60$ years, median 59 years), interval between first diagnosis of head-and-neck cancer and radiotherapy of MSCC ( $\leq 15$ months $v s .>15$ months $(4,16)$ ), visceral metastasis (no vs. yes), other bone metastasis (no vs. yes), cancer site (nasopharynx $v s$. oropharynx $v s$. hypopharynx $v s$. larynx $v s$. other 
sites), gender, time developing motor deficits (1-7 days vs. $>7$ days (17)), ambulatory status prior to radiotherapy (not ambulatory $v s$. ambulatory), number of vertebrae affected by MSCC, (1-2 vs. $\geq 3$, median 3), and performance score according to the Eastern Cooperative Oncology Group (ECOG) (1-2 vs. 3-4, median 3). Distributions of all 11 factors are summarized in Table I.

The statistical analyses regarding the post-treatment ambulatory status were performed with the Chi-square test. Factors that achieved significance $(p<0.05)$ were used for the scoring system developed to estimate the probability of being ambulatory at 1 month following irradiation. For each significant factor, a factor score was calculated by dividing the ambulatory rate in percent by 10. The individual score for each patient was received by adding the factor scores.

\section{Results}

Three of the investigated factors showed a significant positive association with the post-treatment ambulatory status, namely time developing motor deficits of $>7$ days $(p=0.011)$, being ambulatory prior to radiotherapy $(p<0.001)$, and an ECOG performance score 1-2 $(p<0.001)$. The post-treatment ambulatory rates of all investigated factors are summarized in Table II. The post-treatment ambulatory rates of the three significant factors were used to develop the scoring system (Table III). The individual scores for the 60 patients were 7 points, 12 points, 15 points, 20 points, 22 points and 27 points, respectively (Figure 1). Three prognostic groups were designed, namely 7-12 points (group A), 15-20 points (group B) and 22-27 points (group C), respectively. The corresponding post-treatment ambulatory rates at 1 month following radiotherapy were $11 \%$ for group A, $62 \%$ for group B and $96 \%$ for group C, respectively $(p<0.001)$. The $\mathrm{p}$-values for the comparisons of groups A vs. B and B vs. C were 0.027 and 0.034 , respectively. In group $\mathrm{C}$, ambulatory rates at 3 months and at 6 months following radiotherapy were $100 \%$ (24 of 24 patients) and $100 \%$ (20 of 20 patients), respectively.

\section{Discussion}

The survival prognosis of patients with locally advanced head-and-neck cancer has been improved due to novel treatment approaches including surgery, radiotherapy and systemic therapies (18-20). Since the risk of developing distant metastasis increases with lifetime, the number of patients presenting with metastatic disease such as MSCC is growing. Radiotherapy alone is the most common treatment for MSCC $(1,2)$. In 2005, a randomized trial of 101 patients that compared radiotherapy alone to radiotherapy plus upfront decompressive surgery showed that selected patients (MSCC from a solid tumor, Karnofsky performance score of 70 or greater, survival prognosis of 3 months or longer, involvement of only one spinal segment by MSCC and paraplegia lasting for not longer than $48 \mathrm{~h}$ ) could benefit from
Table I. Distributions of the evaluated factors.

\begin{tabular}{|c|c|}
\hline & $\begin{array}{l}\text { Number of } \\
\text { patients }(\%)\end{array}$ \\
\hline \multicolumn{2}{|l|}{ Age at the time of irradiation } \\
\hline$\leq 59$ years & $33(55)$ \\
\hline$\geq 60$ years & $27(45)$ \\
\hline \multicolumn{2}{|l|}{$\begin{array}{l}\text { Interval between cancer diagnosis and } \\
\text { radiotherapy of MSCC }\end{array}$} \\
\hline$\leq 15$ months & $25(42)$ \\
\hline$>15$ months & $35(58)$ \\
\hline \multicolumn{2}{|l|}{ Visceral metastasis } \\
\hline No & $31(52)$ \\
\hline Yes & $29(48)$ \\
\hline \multicolumn{2}{|l|}{ Other bone metastasis } \\
\hline No & $27(45)$ \\
\hline Yes & $33(55)$ \\
\hline \multicolumn{2}{|l|}{ Cancer site } \\
\hline Nasopharynx & $8(13)$ \\
\hline Oropharynx & $16(27)$ \\
\hline Hypopharynx & $9(15)$ \\
\hline Larynx & $11(18)$ \\
\hline Other sites & $16(27)$ \\
\hline \multicolumn{2}{|l|}{ Gender } \\
\hline Female & $9(15)$ \\
\hline Male & $51(85)$ \\
\hline \multicolumn{2}{|l|}{ Time developing motor deficits } \\
\hline $1-7$ days & $21(35)$ \\
\hline$>7$ days & $39(65)$ \\
\hline \multicolumn{2}{|l|}{ Pre-treatment ambulatory status } \\
\hline Not ambulatory & $19(32)$ \\
\hline Ambulatory & $41(68)$ \\
\hline \multicolumn{2}{|l|}{ Number of affected vertebrae } \\
\hline $1-2$ & $28(47)$ \\
\hline$\geq 3$ & $32(53)$ \\
\hline \multicolumn{2}{|l|}{ ECOG performance score } \\
\hline $1-2$ & $28(47)$ \\
\hline $3-4$ & $32(53)$ \\
\hline \multicolumn{2}{|l|}{ Fractionation regimen } \\
\hline Short-course radiotherapy $(1 \times 8 \mathrm{~Gy}, 5 \times 4 \mathrm{~Gy})$ & $14(23)$ \\
\hline $10 \times 3 \mathrm{~Gy}$ & $25(42)$ \\
\hline Longer-course radiotherapy (total doses $>30 \mathrm{~Gy}$ ) & $21(35)$ \\
\hline
\end{tabular}

MSCC: Metastatic spinal cord compression; ECOG: Eastern Cooperative Oncology Group.

the addition of surgery with respect to post-treatment ambulatory status and survival (6). In general, these criteria are met by $10-15 \%$ of patients with MSCC. Insufficient response to radiotherapy is considered another good indication for decompressive surgery plus stabilization $(1,2)$. Therefore, it would be helpful to be able to predict the response prior to the start of treatment. From the patient's point of view, post-treatment ambulatory status is a major key point with respect to their quality of life. From the physician's point of view, it is very important to know prior to assigning a treatment to a patient whether the ability to walk can be 
Table II. Post-treatment ambulatory status.

\begin{tabular}{|c|c|c|c|}
\hline & \multicolumn{2}{|c|}{ Number of patients $(\%)$} & \multirow[b]{2}{*}{$p$-Value } \\
\hline & Ambulatory & Not ambulatory & \\
\hline \multicolumn{4}{|l|}{ Age at the time of irradiation } \\
\hline$\leq 59$ years & $22(67)$ & $11(33)$ & \\
\hline$\geq 60$ years & $15(56)$ & $12(44)$ & 0.844 \\
\hline \multicolumn{4}{|l|}{$\begin{array}{l}\text { Interval between cancer diagnosis and } \\
\text { radiotherapy of MSCC }\end{array}$} \\
\hline$\leq 15$ months & $12(48)$ & $13(52)$ & \\
\hline$>15$ months & $25(71)$ & $10(29)$ & 0.340 \\
\hline \multicolumn{4}{|l|}{ Visceral metastasis } \\
\hline No & $23(74)$ & $8(26)$ & \\
\hline Yes & $14(48)$ & $15(52)$ & 0.231 \\
\hline \multicolumn{4}{|l|}{ Other bone metastasis } \\
\hline No & $19(70)$ & $8(30)$ & \\
\hline Yes & $18(55)$ & $15(45)$ & 0.650 \\
\hline \multicolumn{4}{|l|}{ Cancer site } \\
\hline Nasopharynx & $6(75)$ & $2(25)$ & \\
\hline Oropharynx & $9(56)$ & $7(44)$ & \\
\hline Hypopharynx & $7(78)$ & $2(22)$ & \\
\hline Larynx & $6(55)$ & $5(45)$ & \\
\hline Other sites & $9(56)$ & $7(44)$ & 0.987 \\
\hline \multicolumn{4}{|l|}{ Gender } \\
\hline Female & $6(67)$ & $3(33)$ & \\
\hline Male & $31(61)$ & $20(39)$ & 0.987 \\
\hline \multicolumn{4}{|l|}{ Time developing motor deficits } \\
\hline 1-7 days & $7(33)$ & $14(67)$ & \\
\hline$>7$ days & $30(77)$ & $9(23)$ & 0.011 \\
\hline \multicolumn{4}{|l|}{ Pre-treatment ambulatory status } \\
\hline Not ambulatory & $2(11)$ & $17(89)$ & \\
\hline Ambulatory & $35(85)$ & $6(15)$ & $<0.001$ \\
\hline \multicolumn{4}{|l|}{ Number of affected vertebrae } \\
\hline $1-2$ & $17(61)$ & $11(39)$ & \\
\hline$\geq 3$ & $20(63)$ & $12(37)$ & 0.999 \\
\hline \multicolumn{4}{|l|}{ ECOG performance score } \\
\hline $1-2$ & $27(96)$ & $1(4)$ & \\
\hline $3-4$ & $10(31)$ & $22(69)$ & $<0.001$ \\
\hline \multicolumn{4}{|l|}{ Fractionation regimen } \\
\hline Short-course radiotherapy $(1 \times 8$ Gy, $5 \times 4$ Gy $)$ & $6(43)$ & $8(57)$ & \\
\hline $10 \times 3 \mathrm{~Gy}$ & $15(60)$ & $10(40)$ & \\
\hline Longer-course radiotherapy (total doses $>30 \mathrm{~Gy}$ ) & $16(76)$ & $5(24)$ & 0.566 \\
\hline
\end{tabular}

MSCC: Metastatic spinal cord compression; ECOG: Eastern Cooperative Oncology Group; bold $p$-values: significant values.

achieved with radiotherapy alone or upfront surgery is required. This information can be provided with the help of a scoring system predicting the probability to be ambulatory following radiotherapy alone. Two systems have already been developed for patients with MSCC in general, but not for specific tumor entities $(4,21)$. Therefore, the present study has been conducted in order to develop such a scoring system particularly for MSCC from head-and-neck cancer. Based on three predictive factors, time developing motor deficits prior to radiotherapy, pre-treatment ambulatory status and ECOG performance score, three prognostic groups were designed with significantly different post-treatment ambulatory rates of $11 \%$ (group A), 62\% (group B) and 96\% (groups C), respectively. Patients of group A have a low probability of being ambulatory following radiotherapy alone and would likely benefit from the addition of upfront decompressive surgery, particularly if they meet the criteria of the randomized trial of Patchell et al. (6). The post-treatment ambulatory rate of group B patients is also not optimal. Thus, for these patients, upfront surgery may be considered. In group $\mathrm{C}$, the post-treatment ambulatory rates at 1, 3 and 6 months following radiotherapy were extremely high with 


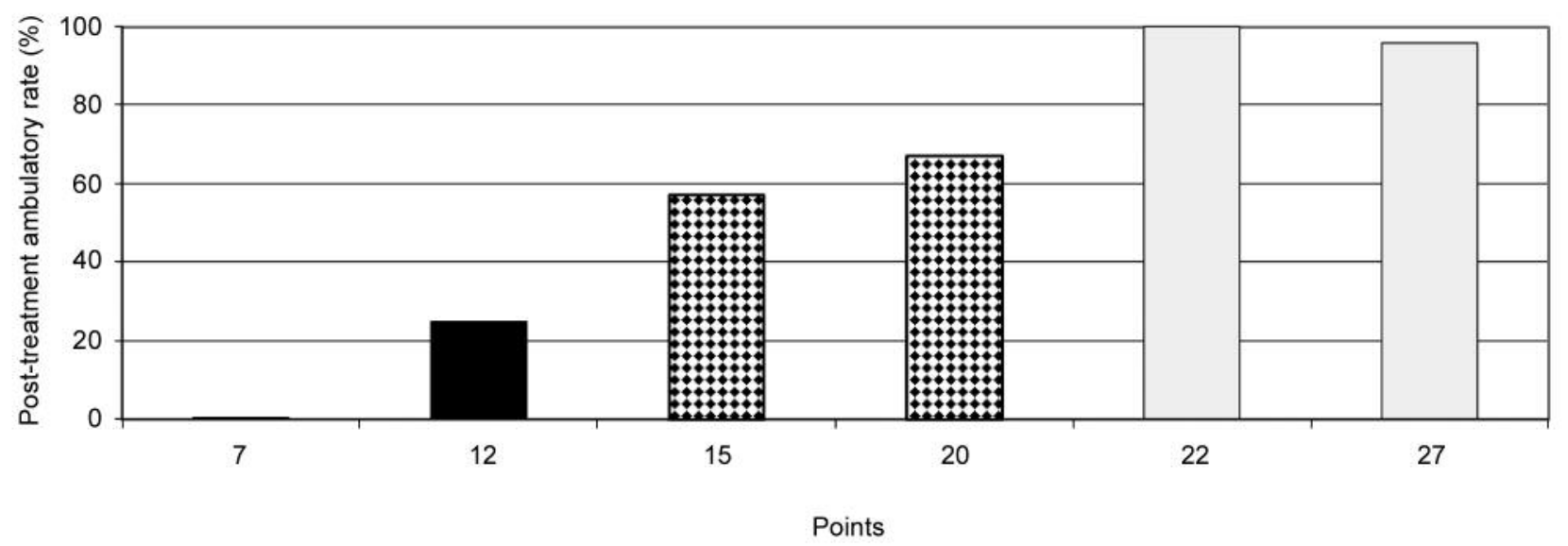

Figure 1. Post-treatment ambulatory rates related to the scoring points.

Table III. Points for the factors included in the scoring system received by dividing post-treatment ambulatory rates (on \%) by 10 .

\begin{tabular}{lcc}
\hline & $\begin{array}{c}\text { Post-treatment } \\
\text { ambulatory rate (\%) }\end{array}$ & Points \\
\hline Time developing motor deficits & 33 & 3 \\
1-7 days & 77 & 8 \\
$\quad>7$ days & 11 & 1 \\
Pre-treatment ambulatory status & 85 & 9 \\
$\quad$ Not ambulatory & & \\
$\quad$ Ambulatory & 96 & 10 \\
ECOG performance score & 31 & 3 \\
1-2 & & \\
\hline
\end{tabular}

ECOG: Eastern Cooperative Oncology Group.

$96 \%, 100 \%$ and $100 \%$, respectively. Therefore, these patients appear well treated with radiotherapy alone and may not require upfront surgery. When following these suggestions, the retrospective nature of the data used to create the scoring system should be taken into consideration. Retrospective data are always associated with a risk of hidden selection biases. However, due to the fact that patients with MSCC from headand-neck cancer are rare, prospective studies focusing on this group of patients will be very unlikely in the near future.

In this study, three predictive factors were identified regarding the ambulatory status after radiotherapy for MSCC from head-and-neck cancer. Based on these factors, a scoring system including three prognostic groups was developed. This system can help predict the probability of being ambulatory after radiotherapy alone and identify patients who could benefit from upfront decompressive surgery in this particular group of cancer patients.

\section{Conflicts of Interest}

On behalf of all Authors, the corresponding Author states that there is no conflict of interest related to this study.

\section{References}

1 Rades D and Abrahm JL: The role of radiotherapy for metastatic epidural spinal cord compression. Nat Rev Clin Oncol 7: 590598, 2010.

2 Prasad D and Schiff D: Malignant spinal cord compression. Lancet Oncol 6: 15-24, 2005.

3 Rades D, Stalpers LJA, Veninga T, Schulte R, Hoskin PJ, Obralic N, Bajrovic A, Rudat V, Schwarz R, Hulshof MC, Poortmans P and Schild SE: Evaluation of five radiation schedules and prognostic factors for metastatic spinal cord compression in a series of 1304 patients. J Clin Oncol 23: 3366-3375, 2005.

4 Rades D, Douglas S, Huttenlocher S, Rudat V, Veninga T, Stalpers LJ, Basic H, Karstens JH, Hoskin PJ, Adamietz IA and Schild SE: Validation of a score predicting post-treatment ambulatory status after radiotherapy for metastatic spinal cord compression. Int J Radiat Oncol Biol Phys 79: 1503-1506, 2011.

5 Rades D, Šegedin B, Conde-Moreno AJ, Garcia R, Perpar A, Metz M, Badakhshi H, Schreiber A, Nitsche M, Hipp P, Schulze W, Adamietz IA, Norkus D, Rudat V, Cacicedo J and Schild SE: Radiotherapy with 4 Gy $\times 5$ versus 3 Gy $\times 10$ for metastatic epidural spinal cord compression: final results of the SCORE-2 trial (ARO 2009/01). J Clin Oncol 34: 597-602, 2016.

6 Patchell R, Tibbs PA, Regine WF, Payne R, Saris S, Kryscio RJ, Mohiuddin M and Young B: Direct decompressive surgical resection in the treatment of spinal cord compression caused by metastatic cancer: a randomised trial. Lancet 366: 643-648, 2005.

7 Rades D, Huttenlocher S, Bajrovic A, Karstens JH, Adamietz IA, Kazic N, Rudat V and Schild SE: Surgery followed by radiotherapy versus radiotherapy alone for metastatic spinal cord compression from unfavorable tumors. Int J Radiat Oncol Biol Phys 81: e861-868, 2011. 
8 Rades D, Huttenlocher S, Dunst J, Bajrovic A, Karstens JH, Rudat $\mathrm{V}$ and Schild SE: Matched pair analysis comparing surgery followed by radiotherapy and radiotherapy alone for metastatic spinal cord compression. J Clin Oncol 28: 3597-3604, 2010.

9 Janssen S, Bolm L, Käsmann L, Bartscht T and Rades D: Palliative radiation therapy for spinal cord compression from metastatic soft tissue sarcoma. In Vivo 30: 529-531, 2016.

10 Rades D, Douglas S and Schild SE: A validated survival score for breast cancer patients with metastatic spinal cord compression. Strahlenther Onkol 189: 41-46, 2013.

11 Janssen S, Bartscht T and Rades D: Prognosis of patients with metastatic spinal cord compression from adrenocortical carcinoma. In Vivo 30: 717-719, 2016

12 Rades D, Douglas S, Veninga T and Schild SE: A validated survival score for patients with metastatic spinal cord compression from non-small cell lung cancer. BMC Cancer 12: 302, 2012.

13 Rades D, Douglas S, Veninga T, Bajrovic A, Stalpers LJ, Hoskin PJ, Rudat V and Schild SE: A survival score for patients with metastatic spinal cord compression from prostate cancer. Strahlenther Onkol 188: 802-806, 2012.

14 Bolm L, Janssen S, Bartscht T and Rades D: Radiotherapy alone for malignant spinal cord compression in young men with seminoma. Anticancer Res 36: 2033-2034, 2016.

15 Douglas S, Schild SE and Rades D: Metastatic spinal cord compression in patients with cancer of unknown primary. Estimating the survival prognosis with a validated score. Strahlenther Onkol 188: 1048-1051, 2012.

16 Rades D, Douglas S, Veninga T, Stalpers LJ, Hoskin PJ, Bajrovic A, Adamietz IA, Basic H, Dunst J and Schild SE: Validation and simplification of a score predicting survival in patients irradiated for metastatic spinal cord compression. Cancer 116: 3670-3673, 2010.
17 Rades D, Conde-Moreno AJ, Garcia R, Veninga T and Schild SE: A tool to estimate survival of elderly patients presenting with metastatic epidural spinal cord compression (MESCC) from cancer of unknown primary. Anticancer Res 35: 6219-6222, 2015.

18 Seidl D, Janssen S, Strojan P, Hakim SG, Wollenberg B, Schild $\mathrm{SE}$ and Rades D: Importance of chemotherapy and radiation dose after microscopically incomplete resection of stage III/IV head and neck cancer. Anticancer Res 36: 2487-2491, 2016.

19 Rades D, Janssen S, Bajrovic A, Strojan P and Schild SE: A total radiation dose of $70 \mathrm{~Gy}$ is required after macroscopically incomplete resection of squamous cell carcinoma of the head and neck. Anticancer Res 36: 2989-2992, 2016.

20 Bonomo P, Desideri I, Loi M, Mangoni M, Sottili M, Marrazzo L, Talamonti C, Greto D, Pallotta S and Livi L: Anti PD-L1 DUrvalumab combined with Cetuximab and RadiOtherapy in locally advanced squamous cell carcinoma of the head and neck: A phase I/II study (DUCRO). Clin Transl Radiat Oncol 9: 4247, 2018.

21 Rades D, Evers JN, Rudat V, Bajrovic A, Karstens JH and Schild SE: A validated score estimating ambulatory status following radiotherapy of elderly patients for metastatic spinal cord compression. BMC Cancer 14: 589, 2014.
Received June 20, 2018

Revised June 22, 2018

Accepted June 25, 2018 